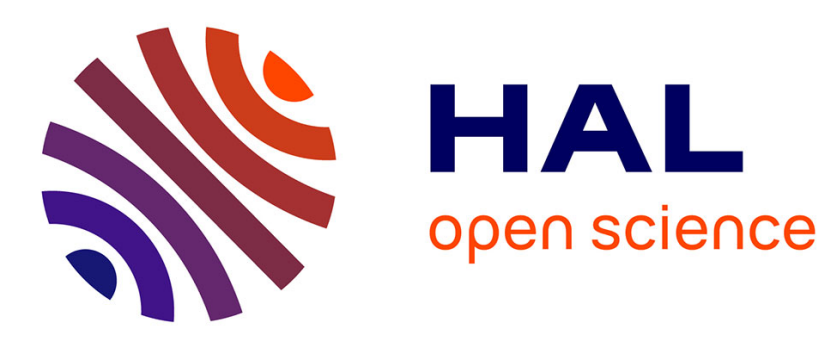

\title{
An experience of young software engineers' employability in the Moroccan offshore industry \\ Vincent Ribaud, Philippe Saliou
}

\section{To cite this version:}

Vincent Ribaud, Philippe Saliou. An experience of young software engineers' employability in the Moroccan offshore industry. IEEE EDUCON2012 Collaborative Learning \& New Pedagogic Approaches in Engineering Education, Apr 2012, Marrakech, Morocco. pp.1-7, 10.1109/EDUCON.2012.6201187 . hal-00769821

\section{HAL Id: hal-00769821 \\ https://hal.univ-brest.fr/hal-00769821}

Submitted on 3 Jan 2013

HAL is a multi-disciplinary open access archive for the deposit and dissemination of scientific research documents, whether they are published or not. The documents may come from teaching and research institutions in France or abroad, or from public or private research centers.
L'archive ouverte pluridisciplinaire HAL, est destinée au dépôt et à la diffusion de documents scientifiques de niveau recherche, publiés ou non, émanant des établissements d'enseignement et de recherche français ou étrangers, des laboratoires publics ou privés. 


\title{
An experience of young software engineers' employability in the Moroccan offshore industry
}

\author{
Philippe Saliou, Vincent Ribaud \\ Université de Brest, UEB \\ LabSTICC \\ Brest, France \\ \{psaliou, ribaud\}@univ-brest.fr
}

\begin{abstract}
Last few years, French customers' demand for relocation of part of IT projects has allowed the emergence of an offshore software development industry in Morocco. A network of eight Moroccan universities and the University of Brest has set up a mobility scheme for Moroccan Master students. The OTI programme "Offshoring des Technologies de l'Information" is governed by the strong principle of driving skilled young engineers to the benefit of Morocco economic development. Education in Morocco and France is specialized on the issue of software development. The mobility scheme should help to reduce the socio-cultural distance that is inherent to offshore software projects. Without neglecting the need of the good quality of academic education, the programme success relies also on complementary actions: students' selection in Morocco; welcome and support in France; search, placement and follow-up of internships in France with pre-employment in Morocco. This article presents original points of the programme and an evaluation using criteria related to students' needs, business demand and institutions requirements.
\end{abstract}

Keywords-component; students' mobility, employability, global software development

\section{INTRODUCTION}

"Global software development seems to have become a business necessity for various reasons, including cost, scarcity of resources, and the need to locate development closer to the customers [1]". The industry of information technology in Morocco has a rapid growth thanks to offshore practices within a global company where mixed teams of employees in France and Morocco produce or maintain information systems for customers which are mainly French. Although this young offshore industry benefits from the feedback of a comprehensive development model, they are faced to the wellknown problems of Global Software Development (GSD). 10 years ago, [2] introduced a special issue of IEEE Software with the dimensions of the GSD problem: strategic issues, cultural differences, communication among stakeholders, knowledge management, topics related to project management and processes, and of course the technical difficulties. Most of these dimensions have to be addressed by management and organization of the extended company, but a good preparation for young engineers to these new challenges is an important issue for which the Moroccan-French experience presented in this article was designed and implemented.

This article describes two aspects of a mobility programme called OTI - Offshoring of Information Technology
(Offshoring des Technologies de l'Information), intended to final year students of Moroccan universities' Master of Computing. The role of the University of Brest, in addition to hosting students for a semester, is to coordinate the round trip among French and Moroccan components of firms performing GSD between France and Morocco. Without neglecting the challenges and difficulties of providing a high-level academic education, this article focuses on extra-academic aspects, especially the employability of beneficiaries of the OTI programme. The individual dimension is taken into account through the cultural and communication issues discussed in sections II and IV. Elements related to the societal dimension especially institutional constraints - are exposed in $\S$ II.C and used in Section IV to evaluate the OTI programme. The OTI programme itself is described in Section III. We conclude with a brief conclusion.

\section{ISSUES ANALYSIS}

\section{A. Cultural issues}

In the literature, the notion of distance is considered as a major factor impacting the GSD $[3,4]$. GSD teams are usually composed of members from different countries, speaking different languages and with different managerial tradition. For example, [5] reported a case study where employees of an offshore component in the Far East preferred to resign rather than refuse the additional work requested by the Western management. The socio-cultural distance is a complex dimension that includes cultural, linguistic, political aspects, and also individual issues. Several models of cultural dimensions are used in research; one of the most used is that of Hofstede [6], although it is not without detractors. For example, [7] conclude that Hofstede's model is not relevant for studies on software development. Thus we hypothesize that the cultural dimension models are less relevant if we can integrate the cultural differences in the training process. The major players in the Moroccan offshore software industry (Logica, AtoS, Capgemini, HP-CDG) requested us to provide facilities enabling Moroccan and French team members to share periods of several months of "friction". We made a pragmatic response that offers to prospective young Moroccan employees a long enough stay in a French company to understand the professional behavior of French teams. This immersion also helps reduce the cultural distance, both for young Moroccan collaborators and French teams that host them. 


\section{B. Communication issues}

The difficulties of communication in a GSD project are emphasized by many authors: "rich communication is most important [8]", "the key challenge of global software engineering is to establish appropriate communication and coordination habits in a global project environment [9]", "The unique characteristics of Global Virtual Teams (GVTs) make the communication among team members a critical indicator of GVTs performance [10]". Most authors propose solutions based either on the media technology [3], or on management practices and information sharing [9], or on techniques reducing the temporal or geographical distance [4]. To the extent that these practices are within the purview of software companies, our academic approach is intended to improve oral and written communication skills in French and to develop documentation practices.

\section{Institutional issues}

The reform of higher education system implemented by Morocco aimed to equip the 14 Moroccan public universities with a greater autonomy, to adapt courses and training to socioeconomic needs and to renovate university curricula based on the model of the European LMD (Bachelor - Licence, Master, Doctorate). To support this reform, a Priority Solidarity Fund called Fonds de Solidarité Prioritaire d'Appui à la Réforme de l'Enseignement Supérieur Marocain (FSP-ARESM) was established in 2004. It covered the areas of governance, teaching - instructional design and research.

Under the instructional design cooperation about computer science, French and Moroccan partners have quickly converged on a proposal for a final internship in France for students of Moroccan Master called Master Offshoring. It was stated that the return to country of origin was a crucial point that only strong institutional governance can guarantee.

To promote youth mobility in the Mediterranean area, a cooperation of 16 countries in 2010 allowed the establishment of the Mediterranean Office for Youth (MOY) (http://www.officemediterraneendelajeunesse.org). This office aims to promote student mobility similarly to the Erasmus programme. The MOY was established in recognition of the fact that circular migration for educational purposes is a decisive factor in the development of wealth, intercultural exchange, and mutual understanding in the Mediterranean region. Since its inception, the MOY issues an annual call for proposals for labeling Master and $\mathrm{PhD}$ programmes. The objective is to facilitate the mobility experience of young people on priority programmes for development of the Mediterranean area and to facilitate youth employment in their country of origin. The MOY label provides significant scholarships that motivate high-level students to apply for labeled programmes. The OTI programme, a candidate for the first call for proposals, has been labeled by the MOY in March 2011.

\section{GSD education programme}

Some universities in Europe and North America offer a training course about Global Software Development / Global Software Engineering. In essence, this type of course is usually held in cooperation with several universities distant in space and / or time. Most of the time, there are group projects that aim to collaborate students or groups of students from different universities [11, 12, 13]. By its very nature, these types of courses teach and use many means of communication and collaboration: instant messaging and asynchronous video conferencing and Internet telephony, collaboration tools, shared resource management systems. Several articles report positive feedback, because the inconveniences inherent in distributed academic projects are meaningful of GSD projects: "Beside their core tasks the students were also challenged by a lot of problems referring to communication issues and organizational coordination. Thus, they could experience how social aspects affect communication [11]". "The difference of nine hours presented a significant difficulty in arranging meetings. Cultural differences also played some role (attending meetings in a timely manner was one of them) [12]". "This would appear to underline the importance of directly addressing known cultural problems in multicultural teaming. The general trend of the students comments for this item was along the lines of "we had a lot of problems in the project but we dealt with them and that was very satisfying [13]".

Some universities offer comprehensive programmes to prepare for software engineering in a multicultural environment. Detroit Mercy University offers over 20 years the International Studies in Software Engineering Programme (ISSE). This programme aims to make the students understand that there are models of practice not originating or being different from their culture of origin and, consequently, aims to equip students with the rules and practices of other cultures [13]. The principal mean of action ISSE programme is the immersion in one or two cultures, which is also our main development tool. The difference lies in the fact that we offer to Moroccan students an experience in a foreign university (ours) and a foreign company (the French component associated with the possible Moroccan employer).

In Europe, we are aware of two European Master programmes in Software Engineering. The programme European Master on Software Engineering (EMSE, http://emse.fi.upm.es/) is a joint initiative of four universities in Blekinge (Sweden), Bolzano (Italy), Kaiserslautern (Germany) and Madrid (Spain). The principle of mobility is to choose two universities and spend a year in each, with obtaining the two Master's degrees on success. The last semester is devoted to the Master's thesis supervised by a master instructor of each university. This case of foreign immersion leading to a double Master's degree is similar to our programme, but as the purpose of the EMSE Master is research, we cannot speak of employability into the Global Software Development market.

The programme Global Software Engineering European Master (GSEEM, http://www.gseem.eu/) is offered by three universities in Västerås (Sweden), L'Aquila (Italy) and Amsterdam (Netherlands). Unlike the EMSE programme, the objective is to prepare future software engineers to work in distributed professional environments. The mobility scheme is the same: a year in the home university, one year in the host university and obtaining two Master's degrees on success. The Master is research-oriented with three specialization profiles: software architecting, real-time embedded systems engineering, web systems and services engineering. Students are well 
prepared for GSD; GSEEM students won the first competition Student Contest on Software Engineering (SCORE) at ICSE 2009 conference.

Compared to existing programmes, our programme differs with its strong career orientation designed to gain a first professional experience in France intended to a preemployment in Morocco.

\section{DESCRIPTION OF THE PROGRAMME OFFSHORING DES TECHNOLOGIES DE L'INFORMATION}

\section{A. Fundamentals Principles}

The issues of mobility and employability are central to the programme since its inception in 2007. Particular attention was paid to the problem of mobile students' evaporation in the host country (the "brain drain") to achieve an ethical and balanced cooperation model. French government bodies as well as teachers of the University of Brest did not want to bring students from Morocco to keep them in France. All the Moroccan participants want their students to work back to Morocco after a successful stay in France. Industrial players involved in the project seek to improve both sides of their extended enterprise: the French side (generally called the front office) in connection with the client and the Moroccan side (generally called the back office) to which is assigned a portion of the offshore development.

The exchange of students and academics between countries is a proven system that usually takes place in intergovernmental arrangements such as Erasmus Mundus. The qualification within the work in a foreign country - a graduation internship, for example - obeys precise laws and complicated regulation that involves far more of actors that an academic exchange ${ }^{1}$.

The partners have therefore agreed:

A founding principle - Acquire a first experience in France and then mobilize the skills for the benefit of economic development of Morocco.

Centralized coordination of mobility and employability - This coordination is supported by the University of Brest; it acts as a hub that connects the Moroccan universities, Moroccan students, future Moroccan employers and French companies working in the offshore software development; it coordinates also the different academic, administrative and legal procedures.

\section{B. Terms of mobility}

The OTI programme includes two measures having a different pattern of mobility.

Since 2007-2008, the measure called "Stage en France avec une pré-embauche au Maroc" (SFM), Internship in France with a pre-employment in Morocco, provides a mobility of a semester. This pattern allows $2^{\text {nd }}$ year Master students to perform their graduation internship in France with the prospect of an employment in Morocco. The University of Brest centralizes and controls the assignments of internship proposals

${ }^{1}$ This explains why universities might be reluctant. issued by French companies' departments (almost all located elsewhere than Brest) performing offshore development with their Moroccan counterparts. On behalf of Moroccan universities, the University of Brest also conducts interns follow-up and internships assessment required to obtain the Moroccan Master's degree.

In 2010, we introduced a second measure based on a mobility of one year. This is a joint Master's degree from the University of Brest and 8 Moroccan universities. The first year of study takes place in Morocco, the second year in France: 6 months of study at Brest followed by a period of 6 months in France with a pre-employment in Morocco. The Master "Offshoring of Information Technology" is one of 33 MOYlabelled Master programmes in March 2011, the only one in the field of Information Technology.

\section{Content of the double Master's degree}

The programme curriculum has been designed to train engineers in software development (design, production and maintenance) of offshore projects. The curriculum does not only focus - as other GSD courses or programs do - on aspects specific to the offshore. The programme objective is to acquire a foundation of skills and knowledge on new technologies and industrialization tools used in large software development companies. It is assumed that the processes, methods, techniques and tools of offshore development vary from company to company and are taught and mastered during the training internship, which should also be a formative period.

While historically the first Moroccan partners followed a common curriculum framework (so-called Offshoring Masters), the first year of Master in Morocco can be performed in four quite different specialties:

- Software development and quality: universities Hassan II Mohammedia (UH2M - Casablanca), Chouaïb Doukkali (UCD - El Jadida) and Ibn Tofaïl (UIT Kenitra) ;

- Networking and Systems: universities Ibn Zohr (UIZ Agadir), Hassan II Mohammedia (UH2M Casablanca), Hassan $1^{\text {er }}$ (UH1 - Settat) and Abdelmalek Essaâdi (UAE - Tanger);

- Information System Engineering: university Cadi Ayyad (UCAM - Marrakech) ;

- Applied Informatics Offshoring: university Mohammed V-Agdal (UH1 - Rabat).

Therefore, the knowledge basement acquired after the first year may vary from student to student and an individual harmonization process is implemented after a prognostic evaluation in three ground subjects: operating systems and networks, databases and information systems, object-oriented programming in Java. Depending on his/her evaluation results, a student attends courses on one, two or three ground subjects over a period of 6 weeks.

From November to March, all students attend 6 technical courses of 60 hours each: object-oriented design, distributed systems, Web technologies, software engineering, information systems, J2EE development. They attend also English and French courses. The 6-months internship lasts from April to September. 


\section{Practical Aspects}

According to mobility measure, students' selection is subject to different rules.

For the internship in France, the selection is made in two stages. First, a screening of the second year Masters students is achieved by each Moroccan university based on the academic performance and the presumed ability of students to comply with the programme ethics and requirements. The internship aims to foster skills for a possible employment in Morocco, and the Human Resources of Moroccan employers perform their recruitment procedures, select candidates that suit them and assign them to an internship in France. In collaboration with each candidate, the University of Brest coordinates the logistics: internship formalities, visa, travel, accommodation..

For the double Master's degree, the number of students is limited to 40 despite of many requests. Each of the nine Masters establishes a shortlist with at most 10 candidates. The screened students pass a knowledge test in Information Technology, the French language test, Test des Connaissances en Français (TCF) and a personal interview with the University of Brest programme manager and his counterpart in each Moroccan Master. Up to 40 students are finally selected. Although the workload is very heavy, this selection process is transparent, understood and agreed by all partners and contributes to the success of the collaboration.

The MOY label provides us with 4 excellence grants of 6500 Euros (for 6 months) and thanks to Logica - our main industrial sponsor, we are able to offer 12 grants of 2000 Euros, assigned on financial criteria. During the 6-months internship, companies provide interns with an allocation between 900 Euros and 1000 Euros per month. Academic fees are cheap in public French universities: around 450 Euros per year, including a good social insurance. The overall cost of the mobility patterns is affordable for many Moroccan students, a key factor to decide them to apply for the programme.

Welcome conditions and stay facilities are a factor for students' success. The OTI programme has forged a close partnership with the CLOUS of Brest (local branch of the national organization whose mission is to facilitate students' lives in many areas: food, housing, scholarships, social and cultural, etc.). The CLOUS provides 50 campus rooms to the OTI programme, which can accommodate all students in the same manner for the cheap price of 215 Euros per month. Students obviously benefit from the logistics of the CLOUS. The graduation internship is almost never performed in Brest, which makes it necessary to offer support from the University of Brest during installation in the French city where the internship takes place.

The OTI programme is based on close collaboration between the international relationships department of the University of Brest, Moroccan universities, the Embassy of France and French consulates in Morocco, Morocco Campus France (branch of the National Agency for the promotion of French higher education abroad) and the prefecture of Finistère (Brest administrative region). This collaboration is essential to support the selected students, including obtaining visas and their permission to stay in France.
The first steps in France are supported by teachers from the University of Brest: welcome on arrival, administrative facilities, and settlement help. Throughout the year, support is provided to students on demand. A successful integration into French society is fundamental to the programme requirements, and university staff has to deal with extra-academic issues.

\section{E. Historical data}

1) Interns counting: Table I shows the number of mobile students in France under the responsibility of the University of Brest between 2007 and 2012. This is a cumulated count of both mobility patterns described in $\S$ III.B.

TABLE I. STUDENTS COUNT BY UNIVERSITY OF ORIGIN

\begin{tabular}{|l|c|c|c|c|c|c|}
\hline \multicolumn{1}{|c|}{ University } & $07-08$ & $08-09$ & $09-10$ & $10-11$ & $11-12$ & $\boldsymbol{\Sigma}$ \\
\hline UIZ-Agadir & 2 & 5 & 4 & 7 & 5 & $\mathbf{2 3}$ \\
\hline UH2M-Casablanca & 2 & 6 & & 11 & 8 & $\mathbf{2 7}$ \\
\hline UCD-El Jadida & & & & 1 & 3 & $\mathbf{4}$ \\
\hline UIT-Kenitra & 2 & 5 & 5 & 13 & 5 & $\mathbf{3 0}$ \\
\hline UCAM-Marrakech & 2 & 5 & & 2 & 4 & $\mathbf{1 3}$ \\
\hline UH1-Rabat & 2 & 3 & 7 & 10 & 6 & $\mathbf{2 8}$ \\
\hline UH1-Settat & 2 & 3 & 2 & & 2 & $\mathbf{9}$ \\
\hline UAE-Tanger & 2 & & 2 & 3 & 2 & $\mathbf{9}$ \\
\hline \multicolumn{1}{|c|}{ Total } & $\mathbf{1 4}$ & $\mathbf{2 7}$ & $\mathbf{2 0}$ & $\mathbf{4 7}$ & $\mathbf{3 5}$ & $\mathbf{1 4 3}$ \\
\hline
\end{tabular}

2) Distribution: Table II shows the number of graduating internships located by city from 2007 to 2011 . Each city is one of the French establishments of a company offshoring software development in Morocco. This is a cumulated count of both mobility patterns described in $\S$ III.B.

TABLE II. GRADUATING INTERNSHIPS COUNT BY LOCATION

\begin{tabular}{|l|c|c|c|c|c|}
\hline \multicolumn{1}{|c|}{ City } & 2008 & 2009 & 2010 & 2011 & $\boldsymbol{\Sigma}$ \\
\hline Amiens & & & & 2 & $\mathbf{2}$ \\
\hline Bordeaux & 3 & 1 & 3 & 15 & $\mathbf{2 2}$ \\
\hline Brest & 2 & 8 & 5 & & $\mathbf{1 5}$ \\
\hline Lille & & & & 3 & $\mathbf{3}$ \\
\hline Lyon & & & & 8 & $\mathbf{8}$ \\
\hline Montpellier & & & & 3 & $\mathbf{3}$ \\
\hline Nantes & 7 & 17 & 3 & 5 & $\mathbf{3 2}$ \\
\hline Paris & & & 7 & 8 & $\mathbf{1 5}$ \\
\hline Rennes & & 1 & & 3 & $\mathbf{4}$ \\
\hline Toulouse & 2 & & 2 & & $\mathbf{4}$ \\
\hline Total & $\mathbf{1 4}$ & $\mathbf{2 7}$ & $\mathbf{2 0}$ & $\mathbf{4 7}$ & $\mathbf{1 0 8}$ \\
\hline
\end{tabular}

\section{EVALUATION}

This section presents an evaluation of the programme regarding the issues presented in Section II.

\section{A. Cultural issues}

Almost all Moroccan students are Muslims and respect Islamic rules that can be unknown and misunderstood in France. Conversely, secularism (for instance, the absence of distinctive religious signs) at school and at work is an important aspect of French society and can be difficult to grasp for Moroccans people. This cultural difference - related to religion - is hardly taken into account in GSD research. 
Nevertheless the knowledge of some fundamental principles and rules helps the understanding of many relational situations. It is quite logical to believe that a semester or one year in France allows Moroccan students to better understand the French customs. It is also likely to think that the integration of young Moroccan men and women in French companies educates the French teams to cultural differences. The University of Brest has sometimes to accompany some French teams to help them understand that we cannot force Moroccan students to fully adopt a Western model and that the workplace must also accept to adapt some cultural principles, such to allow to draw an headscarf at work.

\section{B. Communication issues}

As indicated in section II.B, the concerns associated with methods and tools of communication used in a GSD environment are not specifically addressed in the programme.

In addition to the scientific and technical aspects, the programme offers numerous actions to prepare for employability: a course intended to prepare to professional integration, lectures by industrial workers, workshops simulating job interviews, coaching sessions for job applicants. These activities allow students to better understand the codes of conduct and communication in France. They also help them to be aware that they might have to adapt some attitudes to comply with French culture, for example their dressing or a gregarious way of life.

[15] states that in addition to the official communication, it is necessary to have an informal communication within the team. "We will argue that most of the existing coordination support tools have used formal communication procedures and that there is a need for nurturing informal communication procedures as well [15]". The difficulty to communicate in the same language is a barrier to the use of these two types of communication, and indirectly to team performance [2]. We assume that a long stay in France - including a course in written and oral communication by French teachers - develops the two forms of communication.

\section{Institutional criteria}

This programme was designed in 2009 as a result of the cooperation within the intergovernmental framework FSPARESM. The Mediterranean Office for Youth (MOY) is promoting higher education training programmes that correspond to fields of Mediterranean interest. Programmes shall fulfill several criteria which are:

- Degree of internationalization of programme - in its design, implementation, and the origin of students.

- Academic excellence of the programme - how the proposed programme will contribute to the excellence, innovativeness, and competitiveness of the Mediterranean region.

- Quality of the partnership and of the mobility schemewhat are the complementarities among the partners and how the partnership ensures excellence; and the justification and the relevance of the compulsory mobility requirements.
- Career placement - how the programme responds to the skill needs of the Mediterranean region and how it makes graduates more employable.

- Facilities and services proposed to the students - what are the measures that will be taken to provide information and support to mobile students.

In the remaining of the section, we will discuss some aspects of the programme using the MOY selection criteria.

1) Degree of internationalization: The FSP-ARESM computing cooperation included in its infancy 7 Moroccan universities and three French universities. Mobility patterns between a Moroccan university and a French university were also considered. However all Moroccan partners agreed to participate to a centralized model where the University of Brest coordinates and arbitrates Moroccan universities-business relations. This is a hub model that is fundamentally different from other MOY mobility programmes or other international joint programmes $[13,14]$.

2) Excellence of the programme: We are not aware of any international French-speaking Master's degree, specialized on offshore software development. The programme was jointly established with an objective of employability as a software engineer in the context of extended team. The programme is only a year old and we did not have yet assessment indicators. Without claiming to excellence, we believe that, in the field of computing studies, this programme is the best that the partnership between Moroccan universities and Brest university can achieve.

3) Quality of the partnership and of the mobility scheme: The partnership is built on a successful cooperation (FSPARESM). Mutual trust and a strong concern to protect the interests of all stakeholders provided us with a sound basis. The cooperation worked well because it was built on the feedback from three years of experimentation and adaptation. We gather course assessment, internships follow-up, interns' evaluation by business tutors, companies' feedback on the programme, steering committee remarks. We use these inputs for the continuous improvement of the programme. Two mobility periods of one semester each were considered, but required much more accommodation and transport expenses and twice administrative tasks. The mobility pattern of a year is the most effective compromise in terms of formalities and cost for the student, and also in terms of effort and logistics coordination for the University of Brest. All the initiatives that we know adopt this annual mobility scheme.

4) Career placement: This programme is rooted in the emergence of offshore software development industry in Morocco. From the beginning, the goal is that students can acquire a first experience in France and then mobilize the skills for the benefit of economic development of Morocco. This aim of employability in Morocco drove most organizational choices related to the internships seek and monitoring. For example, seeking an internship is not a student's responsibility but performed by the University of Brest in close partnership with major IT companies that support this programme (Logica, AtoS, Capgemini, HP -CDG). We are also supported by the APEBI, the federation of information technology, 
telecommunications and offshoring in Morocco (http://www.apebi.org.ma/). An overview of employability figures is presented in Section IV.E.

5) Facilities and service provided to the students: The support of mobile students starts when they are selected. Each of them has a Moroccan referee and a French referee that shall answer to any questions, help during the formalities process and assist in logistics until her/his arrival in France. Upon arrival, students are supported until a relative autonomy. During their mobility in France, students have the support of a single referee to answer all their academic and extra-academic concerns: residence permit, registration, housing, banking, insurance, social security, etc.

\section{Students'feedback}

As the programme is running only since one year, we did not establish yet a formal evaluation of the Master degree. The classroom is exclusively composed of Moroccan students and students asked for a co-education with French students. We were only able to offer a few societal and technical conferences issued by industrial stakeholders. Students reported a couple of drawbacks, and we set up few improvements that have to be monitored. The only measured satisfaction index is the increase in the number of applicants at the entrance of the programme: 50 in 2010-2011 and 90 in 2011-2012.

\section{E. Employers'feedback}

While it is possible to carry out satisfaction surveys in major Moroccan companies, it is difficult to correlate the results. The hiring rate after the graduation provides us with a success indication of the programme, although it should also take into account the market and the need for graduates which has considerably decreased in 2011 .

TABLE III. HIRING RATE

\begin{tabular}{|l|c|c|c|c|c|c|c|c|c|}
\hline Company & $\mathbf{0 8}$ & $\mathbf{0 8}$ & $\mathbf{0 9}$ & $\mathbf{0 9}$ & $\mathbf{1 0}$ & $\mathbf{1 0}$ & $\mathbf{1 1}$ & $\mathbf{1 1}$ & $\boldsymbol{\Sigma}$ \\
\hline & Int. & Hire & Int. & Hire & Int. & Hire & Int. & Hire & \\
\hline AtoS & 3 & 3 & 2 & 2 & & & 6 & 3 & $\mathbf{7 3 \%}$ \\
\hline Capgémini & 6 & 6 & 13 & 10 & & & & & $\mathbf{8 4 \%}$ \\
\hline HP-CDG & 2 & 2 & & & & & & & $\mathbf{1 0 0 \%}$ \\
\hline Logica & 3 & 3 & 12 & 6 & 20 & 19 & 41 & 30 & $\mathbf{7 6 \%}$ \\
\hline \multicolumn{1}{|c|}{ Total } & $\mathbf{1 4}$ & $\mathbf{1 4}$ & $\mathbf{2 7}$ & $\mathbf{1 8}$ & $\mathbf{2 0}$ & $\mathbf{1 9}$ & $\mathbf{4 7}$ & $\mathbf{3 3}$ & $\mathbf{7 8 \%}$ \\
\hline
\end{tabular}

Table III shows the number of internships and the number of hires, group by year and by company. The cumulated counts of both mobility patterns give the hiring rate at the end of the internship. Cumulating all enterprises together, 84 of 108 interns were hired by their company, i.e. $78 \%$.

\section{PERSPECTIVES ET CONCLUSION}

The development of the SFM measure is expected, but it is dependent on the market that has tightened in 2011. France issued new laws related to internships and we have to drastically change the SFM measure to fulfill with the law.

This article presented a mobility programme for Moroccan students coming to France, governed by a strong principle of directing skills to the benefit of economic development of
Morocco. The Master education in Morocco and France is specialized on the issue of software development. However, part of the success of this programme is not related to academic education, but additional actions external to the academic courses: students' selection, help and support in France, seeking, assigning and monitoring of internships in France with pre-employment in Morocco. Moreover, unlike many studies where the view is (relatively) one-way - the companies that are outsourcing their development, the OTI programme also takes into account the expectations of Moroccan companies that are insourcing their software development activity.

\section{REFERENCES}

[1] D. Damian and D. Moitra, D., "Guest Editors' Introduction: Global Software Development: How Far Have We Come?," IEEE Software, vol.23, no.5, pp. 17- 19, Sept./Oct. 2006, doi: 10.1109/MS.2006.126.

[2] J.D. Herbsleb and D. Moitra, "Global software development," IEEE Software, vol.18, no.2, pp.16-20, Mar/Apr 2001.

[3] J.D Herbsleb and A. Mockus, "An Empirical Study of Speed and Communication in GloballyDistributed Software Development", IEEE Transactions on Software Engineering, vol. 29, no 3, pp. 1-14, 2003.

[4] E. Carmel, R. Agarwal, "Tactical Approaches for Alleviating Distance in Global Software Development", IEEE Software, vol.18, no.2, pp.1620, Mar/Apr 2001, doi: 10.1109/52.914732.

[5] V. Casey, "Leveraging or Exploiting Cultural Difference?," Fourth IEEE International Conference on Global Software Engineering (ICGSE 2009), pp.8-17, 13-16 July 2009, doi: 10.1109/ICGSE.2009.9

[6] G. Hofstede, Cultures and organizations : software of the mind, London, UK: McGraw-Hill, , 1991.

[7] S. Abufardeh and K. Magel, "The impact of global software cultural and linguistic aspects on Global Software Development process (GSD): Issues and challenges," 4th International Conference on New Trends in Information Science and Service Science, pp.133-138, 11-13 May 2010

[8] E. Carmel, "Thirteen assertions for globally dispersed software development research," Proceedings of the Thirtieth Hawaii International Conference on System Sciences, vol.3, pp.445-452, 7-10 Jan 1997, doi: 10.1109/HICSS.1997.661670

[9] C. Bartelt, M. Broy, C. Herrmann, E. Knauss, M. Kuhrmann, A. Rausch, B. Rumpe, K. Schneider, "Orchestration of Global Software Engineering Projects - Position Paper," Fourth IEEE International Conference on Global Software Engineering, pp.332-337, 13-16 July 2009.

[10] Qingfei Min; Zhenhua Liu; Shaobo Ji; , "Communication Effectiveness in Global Virtual Teams: A Case Study of Software Outsourcing Industry in China," 43rd Hawaii International Conference on System Sciences (HICSS), pp.1-8, 5-8 Jan. 2010, doi: 10.1109/HICSS.2010.111

[11] C. Deiters, C. Herrmann, R. Hildebrandt, E. Knauss, M. Kuhrmann, A Rausch, B. Rumpe, K. Schneider, "GloSE-Lab: Teaching Global Software Engineering," 6th IEEE International Conference on Global Software Engineering (ICGSE), pp.156-160, 15-18 Aug. 2011.

[12] D. Petkovic, R. Todtenhoefer, G. Thompson, "Teaching Practical Software Engineering and Global Software Engineering: Case Study and Recommendations," 36th Annual Frontiers in Education Conference, pp.19-24, 27-31 Oct. 2006, doi: 10.1109/FIE.2006.322377

[13] Mead, N.R.; Shoemaker, D.; Drommi, A.; Ingalsbe, J.; , "An Immersion Program to Help Students Understand the Impact of Cross Cultural Differences in Software Engineering Work," 32nd Annual IEEE International Computer on Software and Applications, (COMPSAC '08), pp.455-459, July-Aug. 2008, doi: 10.1109/COMPSAC.2008.82

[14] P. Lago, H. Muccini, L. Beus-Dukic, I. Crnkovic, S. Punnekkat, H. Van Vliet, H.; , "Towards a European Master Programme on Global Software Engineering," 20th Conference on Software Engineering Education \& Training (CSEET '07), pp.184-194, 3-5 July 2007.

[15] R. E. Kraut and L. A. Streeter, "Coordination in software development", Commun. ACM, vol. 38, no 3, pp. 69-81, March 1995, doi: $10.1145 / 203330.20334$ 
